\title{
El funcionamiento del cine a través del lenguaje del cómic
}

The functioning of cinema through the language of the comic

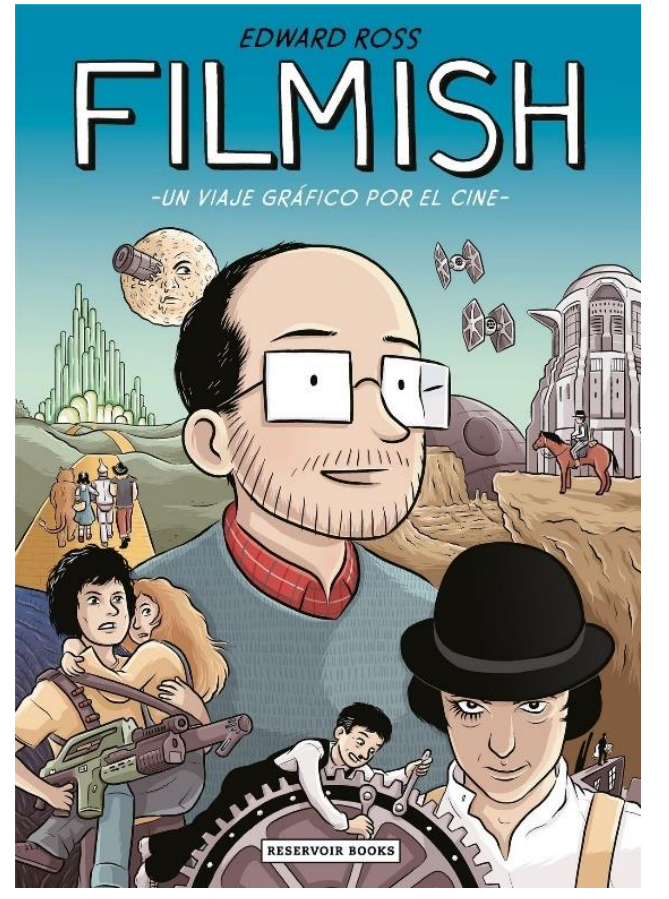

Reseña de: Ross, E., Filmish. Un viaje grafico por el cine (título original: Filmish. A Graphic Journey through Film), Barcelona, Reservoir Books, 2017.

\section{Ana Asión Suñer \\ Universidad de Zaragoza anassu@unizar.es \\ Código ORCID: https://orcid.org/0000-0002- 4850-7869}

Referencia: ASIÓN SUÑER, A., «El funcionamiento del cine a través del lenguaje del cómic», Neuróptica. Estudios sobre el cómic, segunda época, 2, Zaragoza, Prensas de la Universidad de Zaragoza, 2020, pp. 257-260.

Las sinergias y trasvases entre cómic y cine han sido una constante que ha logrado enriquecer tanto temática como formalmente ambos medios. Sin duda su manifestación más inmediata son las recíprocas adaptaciones surgidas al amparo de un público ávido por descubrir cómo se desarrollan sus historias y personajes favoritos en un formato distinto al habitual. Sin embargo, el abanico de confluencias es más amplio, y en ocasiones arroja al mercado propuestas que se alejan de los estándares establecidos. Es el caso de Filmish. Un viaje grafico por el cine, un ensayo teórico que, apoyándose en la versatilidad de las viñetas, apuesta por acercar el funcionamiento y la historia del séptimo arte de una manera amena y didáctica, optando por una estructura ágil y dinámica.

El artífice de esta arriesgada obra es el dibujante, guionista e ilustrador Edward Ross, quien ya había trabajado el uso del cómic como herramienta de divulgación científica en universidades, museos, organizaciones benéficas e 
instituciones de investigación. Su formación en Estudios Cinematográficos, así como su pasión por el noveno arte, dio como resultado la creación de un fanzine teórico en cuatro entregas, que acabó convirtiéndose en el germen de su primer libro: Filmish. Tras su publicación por SelfMadeHero ${ }^{1}$ en 2015 y posterior éxito, fue traducida al español por Carlos Mayor, logrando de nuevo una reseñable acogida entre lectores y críticos. ${ }^{2}$

El libro de Ross se enfrentó al reto de convertir un contenido a priori arduo y denso, en un manual atractivo y cercano. El tratamiento que da a los contenidos no adolece de una erudición que, hasta ese momento, parecía encontrarse únicamente en publicaciones teóricas que prescindían del más mínimo interés por llegar a un público mayoritario. El escritor quiso y supo romper la barrera existente entre academia y sociedad, planteando para ello un producto que tiene el mérito de servir tanto de referencia bibliográfica en las aulas como de lectura para el cinéfilo:

Cuando acabé la Universidad, quería encontrar una manera de seguir hablando sobre cine del mismo modo en que lo hacía allí. Disfrutaba mucho con las ideas que encuentras en ensayos sobre cine y libros académicos, pero tenía la sensación de que las buenas ideas quedaban enterradas en un lenguaje académico muy complicado. Así que cuando me vino la idea de Filmish fue la oportunidad de llevar esas ideas a un público más amplio, y usar el formato del ensayo pero manteniendo las cosas fáciles y comprensibles para ese público más amplio. ${ }^{3}$

Como el séptimo arte, el autor distribuye el material en siete capítulos: el ojo; el cuerpo; los decorados y la arquitectura; el tiempo; la voz y el lenguaje; el poder y la ideología; y la tecnología y la tecnofobia. Una disposición que no resulta casual:

[...] intenté seguir el camino que tomamos como espectadores en una película: empezando por nuestros propios cuerpos viéndola a través de

1 Editorial independiente inglesa especializada en novela gráfica y adaptaciones literarias.

2 Jesús Jiménez en la sección «El cómic en rtve.es» escribió al respecto: «Un libro muy especial que nos permite ver el cine desde otro punto de vista, a la vez que nos recuerda algunas de las películas más interesantes de la historia del Séptimo Arte, lo que siempre es un placer. Cine y cómic más unidos que nunca»: JIMENEZ, J., «"Filmish", un cómic que nos descubre las claves del cine», RTVE, (04-III-2017), https://www.rtve.es/noticias/20170304/filmish-comic-descubreclaves-del-cine/1494840.shtml (fecha de consulta: 16-VI-2020).

3 «Entrevista con Edward Ross sobre "Filmish. Un viaje gráfico por el cine"», Cómic para todos, 23-III-2017, https://comicparatodos.wordpress.com/2017/04/04/entrevista-con-edwardross-sobre-filmish-un-viaje-grafico-por-el-cine/ (fecha de consulta: 16-VI-2020). 
los ojos, después deslizándonos en los cuerpos de los personajes en la pantalla con los que conectamos. Desde ahí, nos relacionamos con el aspecto y el tiempo en la pantalla, antes de que lentamente comprendamos la historia y la ideología de la película según esta avanza. La tecnología parecía una buena manera de finalizar el libro, echando la vista atrás, al nacimiento de la historia del cine, y al futuro. ${ }^{4}$

Una amplia y meticulosa trayectoria con la que consigue abarcar los fundamentos básicos del cine, su mecanismo e historia, una clase magistral impartida por el propio Ross, cuyo alter ego va guiando al lector a través de las 200 páginas de la obra gráfica. El recorrido por el que opta permite establecer una lógica metodológica y temporal, apoyándose a su vez de toda una serie de nombres propios y títulos con los que termina de construir este complejo entramado teórico. En él, nada está dispuesto al azar, y a lo largo de toda la publicación aparecen citas de varias obras teóricas, que se recogen en el apartado final de notas. Además, se realizan puntualizaciones y se invita a profundizar en diversos aspectos, aportando para ello una bibliografía rica y variada.

Las más de trescientas películas que sirven para hilvanar los numerosos datos aportados por el autor -y que, de nuevo, tienen su propia sección al final de la publicación-, son uno de los principales elementos con los que, gracias precisamente a la solución gráfica del propio producto, el usuario consigue familiarizarse con la lectura. El ojo de Viaje a la Luna (1902, George Méliès) da la bienvenida hacia una travesía en la que no faltan las referencias a trabajos tan míticos como Asalto y robo de un tren (1903, Edwin S. Porter), El mago de Oz (1939, Victor Fleming), La naranja mecánica (1971, Stanley Kubrick) o Avatar (2009, James Cameron).

Filmish es una nueva manera de entender el cine, conocer sus entresijos y dejarse llevar por la magia de un medio que permite conocer mejor el mundo y disfrutarlo. El marco para su puesta en escena, el cómic, permite además explotar su esencia y, sobre todo, no privarle de uno de sus componentes básicos: la imagen. Como destacaba Ross al principio de la obra: «[...] el cine puede ofrecernos mucho más que un mero entretenimiento. Es un lugar al que podemos ir para descubrir más sobre nosotros mismos, nuestra cultura y el mundo en el que vivimos». Por todo ello y mucho más, Filmish ha conseguido convertirse en toda una referencia teórica en los estudios sobre el séptimo arte. 